\title{
Movimento, criação e expressão em tempos de pandemia: reflexões sobre o ensino de Educação Física e Artes nos anos iniciais do Ensino Fundamental
}

\author{
Movement, creation and expression during a pandemic outbreak: \\ a reflection on Physical Education and Arts teaching in the early \\ years of primary school
}

\author{
Movimiento, creación y expresión en tiempos de pandemia: \\ reflexiones sobre la enseñanza de Educación Física y Artes en los \\ primeros años de la educación primaria
}

Achilles Alves de Oliveira!

https://orcid.org/0000-000I-7478-0810

Sara Scholze ${ }^{2}$

https://orcid.org/0000-0003-245I-0331

Resumo: Este artigo apresenta uma breve reflexão de dois professores de educação básica considerando possibilidades e desafios do contexto da pandemia de COVID-19, causada pelo novo coronavírus. Para discutir sobre o processo de ensino-aprendizagem nesse contexto, parte-se da experiência de II semanas de ensino mediado por tecnologias nas disciplinas de Educação Física e Artes nos anos iniciais do ensino fundamental em uma instituição de ensino privada do Distrito Federal, Brasil. Busca-se iniciar uma discussão a respeito das mudanças vividas na educação durante esse período e suas possíveis implicações futuras.

Palavras-chave: Educação básica. Ensino on-line. COVID-19.

Abstract: This article presents a brief reflection of two primary education teachers considering possibilities and challenges during the COVID-19 pandemic caused by the new coronavirus. In order to discuss the teachinglearning process in this context, it is based on the experience of II weeks of teaching mediated by technologies in the subjects of Physical Education and Arts in the early years of elementary school in a private educational

\footnotetext{
' Mestre em Educação, Linguagem e Tecnologias pela Universidade Estadual de Goiás (UEG). Professor de educação básica na Secretaria de Estado de Educação do Distrito Federal (SEEDF). E-mail: achillesalves@gmail.com

${ }^{2}$ Mestra em Artes pela Universidade de Brasília (UnB). Professora de educação básica na rede de ensino privado do Distrito Federal. E-mail: sara.scholze@gmail.com
}

Olhar de professor, Ponta Grossa, v. 24, p. I-8, e-15979.045, 2021.

Disponível em <https://revistas2.uepg.br/index.php/olhardeprofessor> 
institution in the Federal District, Brazil. It aims to initiate a discussion about the changes experienced in education during this period and their possible future implications.

Keywords: Primary school. Online teaching. COVID-19.

Resumen: Este artículo presenta una breve reflexión de dos docentes de educación primaria considerando posibilidades y desafíos en el contexto de la pandemia COVID-19 provocada por el nuevo coronavirus. Para discutir el proceso de enseñanza-aprendizaje en ese contexto, se basa en la experiencia de II semanas de la docencia mediada por tecnologías en las asignaturas de Educación Física y Artes en los primeros años de la escuela primaria en una institución educativa privada en Distrito Federal, Brasil. Se buscó iniciar una discusión sobre los cambios experimentados en la educación durante este período y sus posibles implicaciones futuras.

Palabras-clave: Educación primaria. Enseñanza online. COVID-I9.

\section{Introdução}

No contexto escolar, considerando uma realidade geralmente permeada por práticas tradicionais e conteudistas, são comuns os desafios para o desenvolvimento de disciplinas como Educação Física e Artes. Ainda há a presença de um pensamento que supervaloriza aspectos cognitivos em detrimento das demais dimensões do ser humano. Isso, por sua vez, pode conduzir para um afastamento da criança de experiências mais sensíveis, intuitivas e criativas. Além disso, nos anos iniciais do ensino fundamental, para algumas famílias é comum uma preocupação exacerbada com o processo de alfabetização da criança. Contudo, nem sempre se compreende a importância da diversidade de experiências sensoriais, criativas e motoras para que esse processo se consolide da melhor forma possível.

O momento atual traz uma realidade ainda mais delicada para $\circ$ trabalho pedagógico. $A$ pandemia de COVID-19, causada pelo novo coronavírus, tem levado estados e municípios a aderirem a uma série de medidas para seu enfrentamento. No campo educacional, com a suspensão das atividades escolares presenciais, muitas secretarias de educação buscaram alternativas principalmente por meio de atividades não presenciais e pelo ensino virtual.

No Distrito Federal, a primeira suspensão das atividades educacionais se iniciou em II de março de 2020 (DISTRITO FEDERAL, 2020) e, em 24 de março de 2020, foi aprovado no Conselho de Educação do Distrito Federal um parecer permitindo a realização de atividades não presenciais (AFONSO; GASPARINI, 2020). Esse parecer concedeu autorização para que escolas públicas e privadas vinculadas à Secretaria de Educação do Distrito Federal (SEDF) implementassem o ensino mediado por tecnologias.

Com essa medida, a SEDF, assim como as mais diversas instituições de ensino do DF, passou a buscar meios para o planejamento e a implementação de propostas visando minimizar as consequências da pandemia no campo da educação. Sabe-se que os entraves podem ser muitos, como a ausência de domínio de tecnologias digitais de informação e comunicação (TDIC) por parte dos 
professores e a falta ou dificuldade de acesso à internet, principalmente para alunos das áreas periféricas e/ou rurais.

Há de se ressaltar que, mesmo antes da pandemia, já se vivia um constante processo de mudança. Essas transformações geralmente têm ocorrido de forma correlacionada com as inovações tecnológicas digitais (KENSKI, 2013), influenciando diversos campos da sociedade, entre eles, o exercício profissional da docência (LIBÂNEO, 20II). Nesse sentido, conceitos como TDIC e e-learning vêm ganhando espaço na educação, assim como diversos outros que não são abarcados neste texto, como as metodologias ativas e o ensino híbrido.

As TDIC, por vezes também referidas como TIC (tecnologias de informação e comunicação), são definidas pela Unesco (2009, p. 120) como um conjunto composto pelos mais diversos recursos e ferramentas tecnológicas utilizados para "transmitir, armazenar, criar, compartilhar ou trocar informação". No momento atual, as TDIC são parte de um caminho para a educação através do conceito de e-learning. Esse termo vem da junção de e (eletronic) + learning (aprendizagem), correspondendo assim à aprendizagem a distância que se dá mediada pelas tecnologias digitais (MONTEIRO; MOREIRA, 20I8).

A educação mediada por tecnologias, ou mediação tecnológica, é resultado de reflexões acerca da mediação pedagógica com práticas e intervenções que fazem uso de tecnologias nos processos educativos (CARVALHO; SILVA; MILL, 20I8). Por sua vez, o processo de mediação pedagógica é entendido como a ação do professor, com preocupações relacionadas à aprendizagem, voltada à forma como ele trata determinado conteúdo buscando auxiliar o aluno em sua compreensão e apropriação dos saberes e conhecimentos (CARVALHO; SILVA; MILL, 20I8; CRUZ, 2018).

Este texto apresenta uma breve reflexão de dois professores de educação básica a partir de suas atuações em turmas de primeiro e segundo anos do ensino fundamental em uma instituição de ensino particular localizada no Distrito Federal, Brasil. Busca-se refletir sobre possibilidades e desafios para o ensino on-line de Educação Física e Artes em tempos de pandemia. Para isso, discorre-se sobre a experiência de ensino mediado por tecnologias ao longo de II semanas.

O primeiro educador, é licenciado em Educação Física e Pedagogia, com especialização em Psicomotricidade e em Educação e Tecnologias. Tem cerca de 5 anos de experiência como professor de Educação Física e, no momento da redação deste artigo, se encontrava em fase de conclusão do curso de mestrado em Educação, Linguagem e Tecnologias. A segunda educadora, é licenciada em Artes Visuais, mestra em Arte Contemporânea e, no momento desta pesquisa, tinha experiência de 7 anos como professora.

Ambos os professores atuaram na mesma instituição de ensino, onde a carga horária das disciplinas ministradas por eles foi reduzida de duas aulas presenciais de 45 minutos para uma videoaula

Olhar de professor, Ponta Grossa, v. 24, p. I-8, e-I5979.045, 202 I.

Disponível em <https://revistas2.uepg.br/index.php/olhardeprofessor> 
Movimento, criação e expressão em tempos de pandemia: reflexões sobre o ensino...

por semana, de até 10 minutos, a ser postada na plataforma virtual Seesaw3. Para as videoaulas, foram propostas atividades que os alunos deveriam realizar e devolver por meio de fotos e/ou vídeos. As tarefas deveriam ser planejadas considerando sua realização em um tempo máximo de uma hora por semana, conciliadas com a carga horária das demais disciplinas. A cada postagem dos alunos, os professores ofereciam feedback sobre o resultado alcançado. A organização das aulas e atividades teve de ser repensada para se adequar a essa realidade.

\section{Reflexões para o ensino de educação física}

Cada criança parte de uma realidade única, com possibilidades distintas a depender da disponibilidade ou ausência de materiais e/ou espaço físico. No ensino on-line, tem-se a questão da presença de um adulto para mediar e auxiliar em seu processo de aprendizagem, como também a dificuldade quanto à priorização de outras atividades em detrimento das propostas pela Educação Física. Há de se considerar, ainda, que a relação entre o uso de telas e o movimento geralmente se apresenta como algo inversamente proporcional no cotidiano da criança. Quanto maior o acesso a telas, menor costuma ser o tempo em que a criança brinca, se movimenta, explora o espaço. Com as restrições decorrentes da pandemia de COVID-19, dispositivos como tablets, smartphones, videogames, laptops e TVs ganham mais presença, suprindo tanto a ausência de áreas seguras e adequadas para o brincar quanto a necessidade dos responsáveis, em geral ocupados com tarefas domésticas e home office, entre outros.

Nesse sentido, como abarcar a complexidade e diversidade de experiências de forma a promover o desenvolvimento integral das crianças? De que forma pensar a Educação Física e incorporar em sua prática de ensino, mediada por tecnologias, os objetos de conhecimento de cada unidade temática proposta pela Base Nacional Comum Curricular, BNCC (BRASIL, 20I8), dado o contexto da pandemia?

Reforçou-se a demanda de planejar e incorporar atividades considerando a realidade de cada criança, tendo ela uma ampla variedade de ferramentas e equipamentos ou não. $O$ mesmo se aplica quanto ao local e espaço disponível para as atividades: algumas crianças dispõem de grandes áreas para se movimentar, outras, apenas de um corredor como local mais adequado para a prática.

Assim, atividades com excesso de direcionamento podem limitar a adesão das crianças e das famílias, dada a indisponibilidade de materiais e/ou de espaço físico. Por outro lado, um caminho pode ser a aposta em experiências que abordem determinada habilidade, mas deem liberdade para que a criança a desenvolva conforme suas possibilidades. $O$ professor pode partir de uma breve explanação

\footnotetext{
${ }^{3}$ Disponível em https://web.seesaw.me/ ou aplicativo para dispositivos móveis.

Olhar de professor, Ponta Grossa, v. 24, p. I-8, e-15979.045, 2021.

Disponível em <https://revistas2.uepg.br/index.php/olhardeprofessor>
} 
sobre a habilidade, o conteúdo e as expectativas acerca da vivência a ser realizada pela criança, de forma a disponibilizar ferramentas para que, com sua família, o aluno possa utilizar estratégias para a criação e/ou adaptação da atividade. Para isso, alguns aspectos não podem ser desconsiderados pelo educador em seu processo de planejamento.

Antes de tudo, é relevante buscar apresentar às famílias a proposta a ser desenvolvida e a importância das atividades, assim como levantar sugestões e orientações de como elas podem auxiliar nesse processo, por exemplo, evitando fazer cobranças desnecessárias quanto à performance motora das crianças ou reagir de maneira excessivamente negativa ao erro.

Ao selecionar os objetivos de aprendizagem e as estratégias pedagógicas, incorporar aspectos ligados ao jogo e à ludicidade podem ser pontos diferenciais, mesmo que exista dificuldade, visto que, muitas vezes, a criança executará a tarefa individualmente ou apenas com o auxílio de um adulto. Atividades muito tecnicistas podem ser desestimulantes tanto para as crianças quanto para os pais. Além disso, oferecer diferentes níveis de desafio permite que o aluno se mantenha engajado na tarefa, independente de estar em uma fase mais inicial ou avançada daquela habilidade. Quanto à avaliação, dentro do possível, o vídeo da realização da atividade tende a ser um importante recurso, permitindo que o professor ofereça feedback personalizado para auxiliar no aprimoramento das vivências pedagógicas na Educação Física.

\section{Reflexões para o ensino de artes}

O novo formato de aula a que o arte-educador teve de se adequar é restrito, mas também abre possibilidades para outras perspectivas e maneiras de abordar o universo artístico. É preciso pensar a respeito do que a área de conhecimento Artes traz em si, com seus processos, códigos e maneiras de expressar próprios. Dentro das Artes, podemos abarcar as Artes Visuais, as Artes Cênicas, - Audiovisual, a Literatura e a Música. Essas esferas se compõem de especificidades e também podem confluir umas nas outras, caracterizando a transdisciplinaridade.

Nesta reflexão, o foco se volta às Artes Visuais e aos problemas encontrados para tratar a disciplina no meio digital. Ensinar Artes sem a presença do concreto, da mediação física, do toque e dos debates em sala de aula nos gera um desafio e tanto. Considerando que as aulas em questão têm por base metodológica a Aprendizagem Baseada em Problemas e a Abordagem Triangular (BARBOSA; CUNHA, 2010), várias questões surgiram: como despertar o olhar crítico do aluno para uma obra de arte? Como transformar as aulas on-line em algo a mais do que só meros tutoriais técnicos a serem seguidos?

O contexto de isolamento social nos instiga a buscar alternativas para uma atuação educacional nessa disciplina, que fundamentalmente se ancora na experimentação e materialidade, em especial para

Olhar de professor, Ponta Grossa, v. 24, p. I-8, e-I5979.045, 202 I.

Disponível em <https://revistas2.uepg.br/index.php/olhardeprofessor> 
Movimento, criação e expressão em tempos de pandemia: reflexões sobre o ensino...

os anos iniciais. Portanto, é interessante pensar mais em seus processos e maneiras de encorajar o pensamento do que nas técnicas. É preciso trazer as Artes Visuais para uma nova perspectiva aos alunos de 5 a 8 anos, apresentando artistas, museus, obras e criações de maneira lúdica, a partir dos recursos virtuais, mas também buscando experiências com o palpável. Esse último item é complexo e pode render diversas surpresas, pois o professor está mais para um propositor e não possui o controle dos materiais e suportes escolhidos e explorados por cada aluno.

Porém, é exatamente por isso que a arte-educação se torna também bastante prolífica no formato on-line. $O$ processo criativo e a reflexão de cada aluno resultam em contribuições valiosas para que o educador repense e aprimore suas práticas. $O$ contato com os alunos e suas experiências pode ser, inclusive, mais documentado do que no âmbito presencial, em que o professor está cercado de alunos e muitas vezes não é capaz de acompanhar cada um individualmente. Os registros realizados das suas próprias obras, bem como as gravações de suas apreensões e opiniões sobre o conteúdo apresentado, nos fazem enxergar novas maneiras de estimular o pensamento criativo. Além disso, com a atenção voltada a cada universo particular, é possível notar e valorizar qualidades daqueles alunos que, em sala de aula, nem sempre demonstram todas as suas potencialidades, explorando-as de maneira mais pontual e assertiva, seja por meio de feedbacks, seja da apresentação específica de novas perspectivas.

\section{Considerações finais}

Com essas breves reflexões, buscamos iniciar um diálogo a respeito das possibilidades para a educação a partir das mudanças sofridas no contexto de pandemia de COVID-19. Não houve pretensão de criar manuais ou receitas a serem seguidas para dar aulas e desenvolver conteúdos, mas compartilhar situações e percepções notadas por cada educador em sua atuação. A necessidade de explorar o e-learning fez-se de maneira abrupta e obrigou muitos educadores a reverem suas práticas e rotinas.

Como será a educação daqui a um, cinco ou dez anos ainda não se sabe, mas é possível compreender que o momento atual terá influência sobre a prática educacional do futuro. Será preciso constantemente repensar o como e explorar novos recursos, aliando o motor, o sensorial e o material ao uso das TDIC. Portanto, as experiências vividas hoje podem ser muito valiosas e produtivas para pensar em estratégias e possibilidades de tratar a educação nos anos iniciais do ensino fundamental já nessa nova realidade.

Tais cenários deverão ir além do conteúdo e permitir ao educador explorar habilidades e competências necessárias para a vida pós-pandemia, com suas frequentes mudanças e novidades no âmbito tecnológico e educacional. Com isso, sugere-se que sejam realizadas novas investigações acerca

Olhar de professor, Ponta Grossa, v. 24, p. I-8, e-15979.045, 2021.

Disponível em <https://revistas2.uepg.br/index.php/olhardeprofessor> 
do contexto pedagógico atual, que poderão propor caminhos e alternativas de forma a auxiliar educadores a efetivar um processo de ensino-aprendizagem significativo, inclusivo e de qualidade.

\section{Referências}

AFONSO, M.; GASPARINI, R. Conselho de Educação do DF aprova educação mediada por tecnologia. 2020. Disponível em: http://www.se.df.gov.br/conselho-de-educacao-do-df-aprovaeducacao-mediada-por-tecnologial. Acesso em: 10 jun. 2020.

BARBOSA, A. M.; CUNHA, F. P. (Org.). A abordagem Triangular no ensino das artes e culturas visuais. São Paulo: Cortez, 2010.

BRASIL. Ministério da Educação. Secretaria de Educação Básica. Base Nacional Comum Curricular. 2018. Disponível em:

http://basenacionalcomum.mec.gov.br/images/BNCC_El_EF_II05I8_versaofinal_site.pdf. Acesso em: 10 jun. 2020.

CARVALHO, A. F. et al. Mediação tecnológica. In: MILL, D. (Org.). Dicionário crítico de educação e tecnologias e de educação a distância. Campinas, SP: Papirus, 2018.

CRUZ, D. M. Mediação pedagógica. In: MILL, D. (Org.). Dicionário crítico de educação e tecnologias e de educação a distância. Campinas, SP: Papirus, 2018.

DISTRITO FEDERAL. Decreto ${ }^{\circ} 40.509$, de II de março de 2020. Dispõe sobre as medidas para enfrentamento da emergência de saúde pública de importância internacional decorrente do novo coronavírus, e dá outras providências. DODF, n² 25, Edição Extra, II mar. 2020 Disponível em: https://www.dodf.df.gov.br/index/visualizararquivo/?pasta=2020/03_Mar\%C3\%A7o/DODF\%20025\%20I I-032020\%20EDICAO\%20EXTRA\&arquivo=DODF\%20025\%20I I-03-2020\%20EDICAO\%20EXTRA.pdf. Acesso em: 10 jun. 2020.

KENSKI, V. M. Tecnologias e tempo docente. Campinas: Papirus, 2013.

LIBÂNEO, J. C. Adeus professor, adeus professora? Novas exigências educacionais e profissão docente. 13. ed. São Paulo: Cortez, 20II.

MONTEIRO, A.; MOREIRA, J. A. E-learning. In: MILL, D. (Org.). Dicionário crítico de educação e tecnologias e de educação a distância. Campinas, SP: Papirus, 2018.

SEESAW. Seesaw | Where learning happens. Disponível em: https://web.seesaw.mel. Acesso em: I0 jun. 2020.

UNESCO. Guide to measuring information and communication technologies (ICT) in education. Quebec, Canada: UNESCO-UIS, 2009. Disponível em:

http://uis.unesco.org/sites/default/files/documents/guide-to-measuring-information-and communication-technologies-ict-in-education-en_0.pdf. Acesso em: 4 abr. 2019.

Olhar de professor, Ponta Grossa, v. 24, p. I-8, e-I5979.045, 2021. 
Recebido em: 16 de junho de 2020.

Versão corrigida recebida em: 04 de setembro de 2020

Aceito em: 04 de setembro de 2020.

Publicado online em: 08 de maio de 2021 .

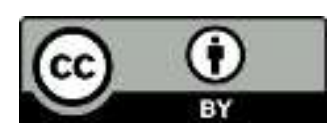

